\title{
Positive central lymph-nodes are underdiagnosed in patients with Bethesda V cytology in an endemic goiter region
}

\author{
Lindsay Hargitai ${ }^{1}$, Stephanie Strobl ${ }^{1}$, Oskar Koperek ${ }^{2}$, Susanne Urach ${ }^{3}$, Wolfgang Raber ${ }^{4}$, \\ Anton Staudenherz ${ }^{5}$, Christian Scheuba ${ }^{1}$, Philipp Riss ${ }^{1}$
}

${ }^{1}$ Section of Endocrine Surgery, Division of General Surgery, Department of Surgery, ${ }^{2}$ Clinical Institute of Pathology, Medical University of Vienna, Vienna, Austria; ${ }^{3}$ Center for Medical Statistics, Informatics, and Intelligent Systems, Institute of Medical Statistics, Vienna, Austria; ${ }^{4}$ Section of Endocrinology, Department of Internal Medicine III, Medical University of Vienna, Vienna, Austria; ${ }^{5}$ Clinical Institute for Nuclear Medicine, Molecular Imaging and Special Endocrinology, University Hospital St. Pölten, St. Pölten, Austria

Contributions: (I) Conception and design: P Riss, S Strobl; (II) Administrative support: P Riss, C Scheuba; (III) Provision of study materials or patients: P Riss, C Scheuba, A Staudenherz, O Koperek, W Raber; (IV) Collection and assembly of data: S Strobl, L Hargitai; (V) Data analysis and interpretation: L Hargitai, S Strobl, S Urach, P Riss, W Raber; (VI) Manuscript writing: All authors; (VII) Final approval of manuscript: All authors. Correspondence to: Stephanie Strobl, MD. Section of Endocrine Surgery, Division of General Surgery, Department of Surgery, Medical University of Vienna, Waehringer Guertel 18-20, Vienna A-1090, Austria. Email: stephanie.strobl@meduniwien.ac.at.

Background: Fine needle aspiration (FNA) is a significant diagnostic procedure for detecting malignancy
in patients with nodular thyroid disease. A high proportion of patients with cytological diagnosed follicular
neoplasia (Bethesda IV and V) ultimately have thyroid cancer. The aim of this study was to evaluate the
incidence of preoperatively undiagnosed central lymph node metastasis in patients with multinodular goiter
(MNG).
Methods: Patients who underwent FNA and were classified as Bethesda IV/V were included. Applying
a radical approach, all patients underwent (hemi)thyroidectomy and prophylactic unilateral central neck
dissection.
Results: During our study period 2009-2013, 60 patients (19.7\%) were classified as Bethesda IV and 21
(6.9\%) Bethesda V. Final histopathological results revealed malignancy in 35 ( $43.2 \%$ ) of 81 Bethesda IV/V
nodules. Of the nodules classified as Bethesda IV, 20 (33.3\%) showed malignancy in the final histology. Ten
patients (16.7\%) had papillary micro-carcinoma (mPTC, <10 mm), 4 (6.6\%) PTC and 6 (10\%) follicular
thyroid cancer. Fifteen of 21 ( $71.4 \%)$ Bethesda V nodules were revealed as PTC of whom seven ( $33.3 \%$ )
patients also had lymph-node metastases.

Conclusions: While $33.3 \%$ of the patients with PTC, preoperatively classified as Bethesda V, had previously undetected positive lymph-nodes, only one patient with Bethesda IV had lymph-node metastasis.

Keywords: Fine needle aspiration (FNA); Bethesda; central neck dissection; follicular neoplasia; lymph node

Submitted Oct 18, 2019. Accepted for publication Jan 17, 2020.

doi: 10.21037 /gs.2020.02.07

View this article at: http://dx.doi.org/10.21037/gs.2020.02.07

\section{Introduction}

Clinically unapparent thyroid nodules are incidentally detected by ultrasound in up to $60 \%$ of European and US populations (1). In iodine-deficient areas (endemic goiter regions), thyroid nodules and even multinodular goiters (MNG) are more frequent, with greater than $90 \%$ being benign $(2,3)$. Thyroid nodules are more common in females, their prevalence increases with age and any history of radiotherapy. In patients with thyroid cancer, lymphnode metastasis can occur in 20-50\% (4).

Fine needle aspiration (FNA) is a well-established, accurate and safe procedure to evaluate thyroid nodules (5). In the literature, the sensitivity and specificity of FNA 
ranges between $56-90 \%(6,7)$. It reduces the rate of unnecessary surgery for patients with benign tumors and can provide helpful information for the surgical treatment $(8,9)$.

The Bethesda System is a world-wide established reporting classification for thyroid cytology and is divided into six categories. Bethesda IV (suspicious for a follicular neoplasm/follicular neoplasm) is associated with a $15-47 \%$ risk for malignancy (10-13). Bethesda $\mathrm{V}$ (suspicious for malignancy) carries a risk of malignancy of 60-75\% (10). Both categories together represent the group of "indeterminate thyroid nodules" (10). Before the Bethesda Criteria, when these two categories were not separated, our group found a $18 \%$ malignancy rate of cytological "follicular neoplasia", with hard lesions to palpation, solitary, and hypoechoic nodules associated with an 2.4-fold, 2.4-fold, and 3.2-fold relative risk of malignancy, respectively (14). A recent study by Manning et al. described a significant increase in the number of cytologically indeterminate nodules and a decrease in benign nodules (15). Therefore, the various therapy options for patients in this population continue to be of great importance.

To date, there is no consensus as to when and to what extent prophylactic central lymph-node dissection (CND) should be performed in patients with indeterminate thyroid nodules (15). Some authors endorse routine CND in clinical nodal-negative patients citing accuracy of staging, reduction in postoperative thyroglobulin, better overall outcome, lower morbidity rate and prevention of a future recurrence (16-21). However, the preoperative detection of lymph node metastasis in the central neck is challenging and they are often only detected histologically after removal of the lymphatic tissue in level VI and VII (22-26). Therefore, without routine prophylactic CND, it must be postulated that they might be missed in many patients. In a study evaluating cytologically indeterminate thyroid nodules and operative strategy, it was shown that prophylactic CND on the ipsilateral side provides sufficient oncological resection and staging with low mortality and avoids reoperation (27). The aim of this study was to assess the incidence of lymph node metastasis in patients with Bethesda IV and V cytology by applying a more aggressive surgical approach.

\section{Methods}

All patients who underwent an operation for MNG with preoperative FNA of the dominant nodule within a fiveyear period [2009-2013] and who signed an informed consent were included in this analysis. MNG is defined as an enlarged thyroid gland with greater than one nodule. The indication for surgery is based on suspicious nodules that demonstrate ultrasound characteristics typical for malignancy, are cold in thyroid scintigraphy and in which FNA determines (possible) malignancy. Clinical data and ultrasound guided FNA results were collected and analyzed. Diagnostic cytology criteria were assessed by the Bethesdaclassification (28). Patients with prior thyroid surgery, age under 18 and/or those with findings suspicious for MTC [elevated serum calcitonin measured according to our institution SOP greater than $6.4 \mathrm{pg} / \mathrm{mL}$ (cut-off limit)] were excluded.

\section{FNA}

Ultrasound-guided FNA was performed in the Department of Endocrinology or Department of Nuclear Medicine. Every patient underwent an ultrasound examination of the thyroid gland and the central and lateral lymphnodes. In addition, ultrasound-guided FNA of the "leading" thyroid nodule was conducted. The leading thyroid nodule was chosen according to size, location and ultrasound characteristics, such as hypoechogenicity, mircocalcifications, taller than wide shape or an ill-defined contour. Cytological and histopathological examinations were performed at the clinical institute of Pathology. A pathologist specialized in thyroid cancer reviewed all specimen again for this study.

\section{Surgery}

All surgical procedures were performed by experienced endocrine surgeons in our university hospital (each having more than 100 thyroid operations per year). In terms of CND, lymphadenectomy of prelaryngeal, pretracheal and uni- or bilateral along the recurrent laryngeal nerve (RLN) was performed after initially mobilizing the upper and lower poles of the thyroid gland $(27,29)$. According to study protocol, all patients with Bethesda IV and V underwent prophylactic CND. Subsequent mobilization of the thyroid lobe cranially and medially allows for optimal visualization and dissection of the RLN (29). Lymphatic tissue along the RLN was dissected before removal of one or both thyroid lobes (29). Thyroidectomies were performed in patients with bilateral MNG, these procedures were accompanied by extended dissection of the recurrent laryngeal nerves using intermittent intraoperative neuromonitoring, as well as 
Table 1 Patient, tumor and lymph-node characteristics

\begin{tabular}{|c|c|c|}
\hline Characteristics & Bethesda IV $(n=60)$ & Bethesda V $(n=21)$ \\
\hline Female:male ratio & $46: 14$ & $16: 5$ \\
\hline \multicolumn{3}{|l|}{ Average sized malignant nodule $(\mathrm{mm})$} \\
\hline Male & 11.9 (range: $0.5-25)$ & 30.7 (range: $12-58)$ \\
\hline Benign histology, n (\%) & $40(66.7 \%)$ & $6(28.6 \%)$ \\
\hline DTC, n (\%) & $20(33.3 \%)$ & $15(71.4 \%)$ \\
\hline Patients with positive lymph-nodes, $\mathrm{n}(\%) ; 95 \% \mathrm{Cl}$ & 1 (1.7\%); 95\% Cl: 0-6 & 7 (33.3\%); 95\% Cl: 3-14 \\
\hline Pos. metastasis to lymph-nodes removed ratio, n (\%) & $1: 11(0.9 \%)$ & $27: 258(10.5 \%)$ \\
\hline
\end{tabular}

DTC, differentiated thyroid carcinoma; 95\% confidence interval, level of confidence that the parameter lies in the interval.

identification and conservation of the parathyroid glands. If this was not possible and a parathyroid gland was damaged, autotransplantation was conducted.

\section{Statistical analyses}

Descriptive statistics analyzed the following parameters: age, gender, tumor characteristics and classification, FNA classification, lymph-node characteristics such as if patients underwent CND and the number of patients with positive lymph-nodes. In addition, mean and standard deviation for metric demographic variables and frequencies including confidence intervals for binary demographic variables were calculated for the total patient population and for the subgroup. Analysis of data was performed using SPSS version 23 for Windows (Chicago, IL, USA).

The study was approved by the local ethics committee of the Medical University Vienna (EK-No.1046/2016) and it conforms to the provisions of in accordance with the Helsinki Declaration as revised in 2013. Informed consent was taken from all the patients.

\section{Results}

\section{Patient characteristics}

Within the 5-year period, a total of 936 patients underwent initial thyroid surgery for unilateral or bilateral MNG; preoperative FNA was performed in 304 (32.4\%). Sixty patients (19.6\%) were classified as Bethesda IV, 21 patients $(6.9 \%)$ as Bethesda $\mathrm{V}$. The remaining patients were classified as following: Bethesda I: 39 patients, Bethesda II: 134 patients, Bethesda III: 10 patients and Bethesda IV: 40 patients. The Bethesda IV group consisted of 46 female and 14 male patients. In this group, 15 females (25\%) had a malignant tumor compared to 5 males $(8 \%)$. The Bethesda $\mathrm{V}$ group contained 16 female and 5 male patients. In this group, 12 females (57\%) had a malignant tumor compared to 2 males $(10 \%)$. Patient characteristics are shown in Table 1.

\section{Surgical procedures}

Of the 60 patients classified as Bethesda IV, 20 (33.3\%) underwent hemi-thyroidectomy and $40(66.7 \%)$ total thyroidectomy. Five (23.8\%) of 21 Bethesda V-patients underwent hemi-thyroidectomy and 16 (76.2\%) thyroidectomy. Frozen section histology during the surgical procedure revealed differentiated thyroid cancer (DTC) significantly more often in patients with Bethesda $\mathrm{V}$ compared to Bethesda IV ( $\mathrm{P}=0.001)$.

\section{Final histological report}

In the patients with cytological Bethesda IV, final histological report revealed DTC in 20 patients (33.3\%). In total, $9(15.0 \%)$ of these patients had papillary microcarcinoma (mPTC, $<10 \mathrm{~mm})$, five $(8.3 \%)$ had PTC 
Table 2 Final pathohistological results according to UICC 2002 of patients with Bethesda IV cytology

\begin{tabular}{lcc}
\hline Variable & pN0 & pN1a \\
\hline PTC & & \\
pT1 & $5(25.0 \%)$ & $1(5.0 \%)$ \\
pT1a & $3(15.0 \%)$ & 0 \\
pT1am & $2(10.0 \%)$ & 0 \\
pT1b & $3(15.0 \%)$ & 0 \\
pT2 & & 0 \\
FTC & $2(10.0 \%)$ & 0 \\
pT1 & $4(20.0 \%)$ & 0 \\
pT2 & & \\
\hline
\end{tabular}

PTC, papillary thyroid carcinoma; FTC, follicular thyroid carcinoma.

Table 3 Final pathohistological results according to UICC 2002 of patients with Bethesda V cytology

\begin{tabular}{lccc}
\hline Variable & pN0 & pN1a & pN1b \\
\hline PTC & & & \\
pT1 & & & \\
pT1a & $2(13.3 \%)$ & 0 & 0 \\
pT1am & 0 & $1(6.7 \%)$ & \\
pT1b & $1(6.7 \%)$ & $1(6.7 \%)$ & 0 \\
pT2 & $3(20.0 \%)$ & $1(6.7 \%)$ & $2(13.3 \%)$ \\
pT3 & $1(6.7 \%)$ & 0 & $1(6.7 \%)$ \\
pT4 & 0 & $2(13.3 \%)$ & 0 \\
\hline
\end{tabular}

PTC, papillary thyroid carcinoma.

$(\geq 10 \mathrm{~mm})$ and six $(10 \%)$ patients had follicular thyroid cancer (FTC).

In the patients with cytological Bethesda $\mathrm{V}$, final histological report revealed DTC in 15 patients (71.4\%). In total, three (14.3\%) had mPTC and $12(57.1 \%)$ patients had PTC.

\section{Lymph nodes}

Of the patients classified as Bethesda IV, CND was performed in $58(96.7 \%)$ with lymph-node metastasis being diagnosed in one patient $(1.7 \%)$. The mean number of removed lymph-nodes was 10.1 (range, $0-37$ ). On the other hand, CND was performed in all patients classified as Bethesda $\mathrm{V}$ in the FNA. Lymph-node metastases were subsequently reported in $7(33.3 \%)$ patients. The mean number of removed lymph-nodes was 27.7 (range, 3-70). Statistical analysis demonstrated significantly higher number of positive lymph-nodes in the Bethesda V-group than the Bethesda IV-group $(\mathrm{P}=0.007)$ (Table 1).

\section{TNM-staging}

In the Bethesda IV group, pT1 was found in 13 (21.7\%) and pT2 in $7(11.7 \%)$ patients. There were no pT3 or pT4 tumors. On the other hand, in the Bethesda V group, $5(23.8 \%)$ patients had tumors pT1, 6 (28.6\%) pT2, pT3 was found in $2(9.5 \%)$ patients, and pT4 was found in 2 $(9.5 \%)$ patient. Statistical analysis demonstrated not only significantly more carcinomas in the Bethesda $\mathrm{V}$ group $(\mathrm{P}=0.002)$, the $\mathrm{T}$-stage was also revealed as statistically significant $(\mathrm{P}=0.002)$.

Final histological classifications and TNM-classifications are shown in Table 2 (Bethesda IV) and Table 3 (Bethesda V).

\section{Morbidity}

Of the 81 patients classified as Bethesda IV or Bethesda V, 11 (13.6\%) had temporary postoperative hypoparathyroidism and required calcium/vitamin D substitution. Eight patients (9.9\%) suffered from temporary unilateral palsy of the recurrent laryngeal nerve. Long term follow-up revealed complete recovery of hypoparathyroidism and/or nerve palsy within six months.

\section{Discussion}

\section{FNA cytology}

Estimating the risk of malignancy in thyroid nodules is essential for determining the best surgical approach. While the American Thyroid Association (30) recommends FNA in patients with MNG and nodules greater than $1 \mathrm{~cm}$ with sonographic suspicious characteristics, other studies suggest that FNA is less useful in patients with MNG due to low sensitivity and high false-negative rates (31-34). FNA in MNG poses some problems given that nodules smaller than ten millimeters are usually not biopsied and in patients with multiple nodules, it may not be possible or feasible as well as uncomfortable for the patient to biopsy all nodules. However, malignancy may still exist in a nodule that is 
not biopsied $(32,35)$. Given that the sensitivity of FNA in MNG patients is low, studies have tried to determine risk factors for malignancy including male gender, young age, fewer number of nodules and small nodule size $(36,37)$. Our study showed quite the opposite. More females had malignant tumors, the average age was 50.3 years and the majority of patients had large nodules. Therefore, our study cannot confirm any of the above-mentioned suggested risk factors for malignancy. However, one must also take into consideration that given the low number of male patients in our study, these results could also be due to a coincidence. In addition, the above-mentioned studies were not conducted in endemic goiter areas, such as Hintze et al., which demonstrated demographic results similar to ours (38). In our study, only $32.4 \%$ of patients underwent FNA, similar to a study conducted in another endemic country where FNA was conducted in only $29 \%$ of patients (32). While Lasithiotakis et al. only experienced $6.7 \%$ suspicious or malignant histopathological results, our study demonstrated a $33 \%$ malignancy rate in Bethesda IV and $71 \%$ malignancy in Bethesda $V$ patients (32). In an endemic goiter region, this study demonstrated a high rate of malignancy, contrary to the incidence of malignancy quoted in the ATA Guidelines 2016 (39). However, when the FNA result is negative, one needs to take into consideration that in an iodine deficient area, a nodule in a MNG that has not been not biopsied may in fact be malignant, even when the leading nodule is biopsied. This also explains the rather small sample size of our cohort. Hence, FNA results need to be considered together with the patients' clinical characteristics in order to determine the best form of therapy.

\section{Prophylactic central neck dissection}

According to the recent ATA-guidelines (American Thyroid Association), prophylactic CND should be considered in patients with PTC who have advanced primary tumors (pT3/pT4) or in patients with clinical involved lateral neck nodes (strong recommendation) (39). In patients with stage $\mathrm{T} 1 / \mathrm{T} 2$, noninvasive, clinical nodenegative tumors and for most follicular cancers, there is only a weak recommendation for thyroidectomy without prophylactic central neck dissection (39). This is in line with the European Society of Endocrine Surgeons (ESES) recommending that routine level 6 prophylactic dissection should be discussed in patients with pT3/pT4 tumors, in patients $>45$ or $<15$ years, male patients, bilateral or multifocal tumors or known involved lateral lymph-nodes. They also recommend that prophylactic lymph-node dissection should be conducted by experienced surgeons only (40).

In our cohort, 81 patients $(26.6 \%)$ of patients were classified as Bethesda IV/Bethesda V, the majority being Bethesda IV (60 patients: 74\%). While 21 (26\%) Bethesda IV patients had thyroid malignancy in the final histology, only one patient had positive lymph-nodes in the upper thoracic aperture. The final histopathological result of this patient was pT1am, pN1 (1/11). According to the approach in our institution and according to the ATA guidelines, this patient would have nevertheless undergone radioiodine ablation therapy (RAI) due to the positive lymph node status, even if the patient did not receive CND (39). According to the ESES-consensus, RAI ablation may be part of the postoperative treatment in selected patients with increased risk of recurrence or risk of spread with multifocal PTC (41). Considering the results of this study and given the fact that only one Bethesda IV patient had positive lymph nodes, prophylactic CND does not seem to be justified in patients with Bethesda IV. It must also be pointed out that six Bethesda IV patients had FTC in the final histopathology. While all specimens undergo frozen section, FTC usually cannot be determined during this examination (42). Therefore, all patients with Bethesda IV, including those with FTC in the final histopathology, underwent prophylactic CND, according to the study protocol.

Fifteen $(75 \%)$ patients with Bethesda V showed DTC of which 7 patients (35\%) also had lymph-node metastases (not detected with preoperative ultrasound). All patients had lymph-node metastases in the central compartment (prelaryngeal, pretracheal, along the RLN left and RLN right), one patient had additional bilateral lymph node metastases along the jugular vein left and right (PTC in both glands), one had further positive ipsilateral lymph nodes along the jugular vein left (PTC left) and one patient also had positive ipsilateral lymph nodes along the jugular vein right (PTC in both glands).

In recent publications, patients who received total thyroidectomy and CND had a statistically lower rate of neck recurrence $(\mathrm{P}<0.01)$, however, the rate of hypocalcemia and transient palsy of the RLN were also significantly higher $(43,44)$. These results also support a study by Lang et al. 2013, which demonstrated a $35 \%$ reduction in the risk of locoregional recurrence in patients that received total thyroidectomy and CND versus total thyroidectomy alone, 
however, the risk of morbidity in terms of postoperative RAI ablation and temporary hypocalcemia was higher (45). Nevertheless, when transient hypocalcemia was removed from the analysis, morbidity was similar in both groups. This has also been observed in past studies (46). Several studies have also shown that total thyroidectomy with central neck dissection can be routinely performed safely by experienced endocrine surgeons, reducing the risk of locoregional occurrence without increasing morbidity or mortality $(29,47)$. The increased risk for transient and permanent hypoparathyroidism, as well as damage to the RLN requires a preoperative critical review of each individual patient and the indication for routine CND. Furthermore, one must consider that most of the patients with lymph-node metastases also had a tumor > pT1a and therefore would also undergo routine RAI (39). Should patients with lymph-node metastases only receive thyroidectomy without CND and postoperative RAI, it can be hypothesized that the RAI would ablate the majority of lymph-node metastases not removed during surgery, given that they were micrometastases. Therefore, CND would not be necessary.

This study demonstrated that lymph node metastases occurred more often than expected. Numerous studies have demonstrated that the presence of lymph-node metastasis has an effect on overall survival (48-52). However, despite the decrease in survival rate, the magnitude of this in young patients is small and in older patient's moderate $(48,53)$. The expected 10-year disease-specific survival rate in older patients lies between $85-95 \%$, while in younger patients it lies between $98-100 \%$ (54). Previous studies demonstrated that lateral lymph-nodes metastases are associated with poorer clinical outcomes, especially in older patients (48$51,53,55)$. On the other hand, several studies have argued that while neck dissection has a significant effect on recurrence, it has no effect on overall survival $(56,57)$.

\section{Complications}

In the opinion of many endocrine surgeons, prophylactic $\mathrm{CND}$ is associated with a higher morbidity to both the parathyroid glands and the RLN. In our institution, hypoparathyroidism is defined as parathyroid hormone levels $<10 \mathrm{ng} / \mathrm{mL}$ with calcium levels below normal $(<2.20 \mathrm{mmol} / \mathrm{L})$ measured for the first time 24 hours after surgery. Nerve palsy was determined and diagnosed via pre- and postoperative laryngoscopy. In terms of transient complications, we had transient hypoparathyroidism in
$17.5 \%$ and transient palsy of the RLN in $10 \%$ in the Bethesda IV group. In the Bethesda V group, 18.6\% of patients exhibited transient hypoparathyroidism and $9.5 \%$ transient palsy of the RLN. Our rates of transient hypoparathyroidism lie well within the literature range of $1.8-51.9 \%(19,58,59)$. In addition, our rates of transient palsy of the RLN also lie with the literature range of $0-10 \%(19,58,59)$. Acceptable rates of permanent hypoparathyroidism lie between $0-14 \%$ and vocal cord palsy between 0 and $5 \%(16,19,60)$. In our patient cohort, we demonstrated a permanent morbidity rate of $0 \%$ regarding hypoparathyroidism and RLN-palsy. Patients who underwent hemithyroidectomy were not included in the statistical analysis for hypoparathyroidism. This may be explained by the experienced high-volume surgeons in our center that performed $\mathrm{CND}$, in accordance to recent studies (29).

\section{Limitations}

Some limitations of the study include a small sample size and the lack of randomization. However, given that all patients were operated with the same standard procedure, both groups can be equally evaluated. In addition, given that most patients presented with multinodular disease, one must consider the challenge of being nodule specific and that the targeted nodule may not be the one that was malignant on histopathology. In order to correlate preoperative findings with pathologic examination, the cytological and histological reports were compared. However, the exact nodule location that was biopsied was not always mentioned in the cytological report. Therefore, a $100 \%$ correlation was not possible.

Given that $33.3 \%$ of the patients with PTC, preoperatively classified as Bethesda $\mathrm{V}$, had previously undetected positive lymph-nodes, the incidence of lymph node metastasis in patients with undetermined thyroid nodules (follicular neoplasia) and Bethesda V-cytology was higher than expected.

\section{Acknowledgments}

Funding: None.

\section{Footnote}

Conflicts of Interest: All authors have completed the ICMJE uniform disclosure form (available at http://dx.doi. 
org/10.21037/gs.2020.02.07). The authors have no conflicts of interest to declare.

Ethical Statement: The authors are accountable for all aspects of the work in ensuring that questions related to the accuracy or integrity of any part of the work are appropriately investigated and resolved. The study was approved by the local ethics committee of the Medical University Vienna (EK-No.1046/2016). Informed consent was taken from all the patients.

Open Access Statement: This is an Open Access article distributed in accordance with the Creative Commons Attribution-NonCommercial-NoDerivs 4.0 International License (CC BY-NC-ND 4.0), which permits the noncommercial replication and distribution of the article with the strict proviso that no changes or edits are made and the original work is properly cited (including links to both the formal publication through the relevant DOI and the license). See: https://creativecommons.org/licenses/by-nc-nd/4.0/.

\section{References}

1. Bongiovanni M, Crippa S, Baloch Z, et al. Comparison of 5-tiered and 6-tiered diagnostic systems for the reporting of thyroid cytopathology: a multi-institutional study. Cancer Cytopathol 2012;120:117-25.

2. American Thyroid Association Guidelines Taskforce on Thyroid N, Differentiated Thyroid C, Cooper DS, et al. Revised American Thyroid Association management guidelines for patients with thyroid nodules and differentiated thyroid cancer. Thyroid 2009;19:1167-214.

3. Gharib H, Papini E, Valcavi R, et al. American Association of Clinical Endocrinologists and Associazione Medici Endocrinologi medical guidelines for clinical practice for the diagnosis and management of thyroid nodules. Endocr Pract 2006; 12:63-102.

4. Papini E, Guglielmi R, Bianchini A, et al. Risk of malignancy in nonpalpable thyroid nodules: predictive value of ultrasound and color-Doppler features. J Clin Endocrinol Metab 2002;87:1941-6.

5. Qubain SW, Nakano S, Baba M, et al. Distribution of lymph node micrometastasis in pN0 well-differentiated thyroid carcinoma. Surgery 2002;131:249-56.

6. Baloch ZW, Sack MJ, Yu GH, et al. Fine-needle aspiration of thyroid: an institutional experience. Thyroid 1998;8:565-9.

7. Morgan JL, Serpell JW, Cheng MS. Fine-needle aspiration cytology of thyroid nodules: how useful is it? ANZ J Surg 2003;73:480-3.

8. Bukhari MH, Niazi S, Hanif G, et al. An updated audit of fine needle aspiration cytology procedure of solitary thyroid nodule. Diagn Cytopathol 2008;36:104-12.

9. Werga P, Wallin G, Skoog L, et al. Expanding role of fine-needle aspiration cytology in thyroid diagnosis and management. World J Surg 2000;24:907-12.

10. Ali SZ. Thyroid cytopathology: Bethesda and beyond. Acta Cytol 2011;55:4-12.

11. Baloch ZW, Fleisher S, LiVolsi VA, et al. Diagnosis of "follicular neoplasm": a gray zone in thyroid fine-needle aspiration cytology. Diagn Cytopathol 2002;26:41-4.

12. DeMay RM. Follicular lesions of the thyroid. W(h)ither follicular carcinoma? Am J Clin Pathol 2000;114:681-3.

13. Smith J, Cheifetz RE, Schneidereit N, et al. Can cytology accurately predict benign follicular nodules? Am J Surg 2005;189:592-5; discussion 595.

14. Raber W, Kaserer K, Niederle B, et al. Risk factors for malignancy of thyroid nodules initially identified as follicular neoplasia by fine-needle aspiration: results of a prospective study of one hundred twenty patients. Thyroid 2000;10:709-12.

15. Manning AM, Yang H, Falciglia M, et al. Thyroid Ultrasound-Guided Fine-Needle Aspiration Cytology Results: Observed Increase in Indeterminate Rate over the Past Decade. Otolaryngol Head Neck Surg 2017;156:611-5.

16. White ML, Gauger PG, Doherty GM. Central lymph node dissection in differentiated thyroid cancer. World J Surg 2007;31:895-904.

17. Docimo G, Tolone S, Ruggiero R, et al. Total thyroidectomy without prophylactic central neck dissection combined with routine oral calcium and vitamin $\mathrm{D}$ supplements: is it a good option to achieve a low recurrence rate avoiding hypocalcemia? A retrospective study. Minerva Chir 2013;68:321-8.

18. Pereira JA, Jimeno J, Miquel J, et al. Nodal yield, morbidity, and recurrence after central neck dissection for papillary thyroid carcinoma. Surgery 2005;138:1095-100, discussion 1100-1.

19. Giordano D, Valcavi R, Thompson GB, et al. Complications of central neck dissection in patients with papillary thyroid carcinoma: results of a study on 1087 patients and review of the literature. Thyroid 2012;22:911-7.

20. Raffaelli M, De Crea C, Sessa L, et al. Prospective evaluation of total thyroidectomy versus ipsilateral versus 
bilateral central neck dissection in patients with clinically node-negative papillary thyroid carcinoma. Surgery 2012;152:957-64.

21. Sadowski BM, Snyder SK, Lairmore TC. Routine bilateral central lymph node clearance for papillary thyroid cancer. Surgery 2009;146:696-703; discussion -5 .

22. Gorges R, Eising EG, Fotescu D, et al. Diagnostic value of high-resolution B-mode and power-mode sonography in the follow-up of thyroid cancer. Eur J Ultrasound 2003;16:191-206.

23. Sugitani I, Fujimoto Y, Yamada K, et al. Prospective outcomes of selective lymph node dissection for papillary thyroid carcinoma based on preoperative ultrasonography. World J Surg 2008;32:2494-502.

24. Shimamoto K, Satake H, Sawaki A, et al. Preoperative staging of thyroid papillary carcinoma with ultrasonography. Eur J Radiol 1998;29:4-10.

25. Roh JL, Park JY, Kim JM, et al. Use of preoperative ultrasonography as guidance for neck dissection in patients with papillary thyroid carcinoma. J Surg Oncol 2009;99:28-31.

26. Park JS, Son KR, Na DG, et al. Performance of preoperative sonographic staging of papillary thyroid carcinoma based on the sixth edition of the AJCC/ UICC TNM classification system. AJR Am J Roentgenol 2009;192:66-72.

27. Asari R, Niederle BE, Scheuba C, et al. Indeterminate thyroid nodules: a challenge for the surgical strategy. Surgery 2010;148:516-25.

28. Cibas ES, Ali SZ. The 2017 Bethesda System for Reporting Thyroid Cytopathology. J Am Soc Cytopathol 2017;6:217-22.

29. Selberherr A, Riss P, Scheuba C, et al. Prophylactic "First-Step" Central Neck Dissection (Level 6) Does Not Increase Morbidity After (Total) Thyroidectomy. Ann Surg Oncol 2016;23:4016-22.

30. Cooper DS, Doherty GM, Haugen BR, et al. Management guidelines for patients with thyroid nodules and differentiated thyroid cancer. Thyroid 2006;16:109-42.

31. Rios A, Rodriguez JM, Galindo PJ, et al. Utility of fineneedle aspiration for diagnosis of carcinoma associated with multinodular goitre. Clin Endocrinol (Oxf) 2004;61:732-7.

32. Lasithiotakis K, Grisbolaki E, Koutsomanolis D, et al. Indications for surgery and significance of unrecognized cancer in endemic multinodular goiter. World J Surg 2012;36:1286-92.

33. Kaliszewski K, Diakowska D, Wojtczak B, et al. Fine-
Needle Aspiration Biopsy as a Preoperative Procedure in Patients with Malignancy in Solitary and Multiple Thyroid Nodules. PLoS One 2016;11:e0146883.

34. Raber W, Kmen E, Kaserer K, et al. The "cold" nodule of the thyroid gland: 20 years experience with 2,071 patients and diagnostic limits of fine needle biopsy. Wien Klin Wochenschr 1997;109:116-22.

35. Campbell MJ, Seib CD, Candell L, et al. The underestimated risk of cancer in patients with multinodular goiters after a benign fine needle aspiration. World J Surg 2015;39:695-700.

36. Rago T, Fiore E, Scutari M, et al. Male sex, single nodularity, and young age are associated with the risk of finding a papillary thyroid cancer on fine-needle aspiration cytology in a large series of patients with nodular thyroid disease. Eur J Endocrinol 2010;162:763-70.

37. Botrugno I, Lovisetto F, Cobianchi L, et al. Incidental carcinoma in multinodular goiter: risk factors. Am Surg 2011;77:1553-8.

38. Hintze G, Windeler J, Baumert J, et al. Thyroid volume and goitre prevalence in the elderly as determined by ultrasound and their relationships to laboratory indices. Acta Endocrinol (Copenh) 1991;124:12-8.

39. Haugen BR, Alexander EK, Bible KC, et al. 2015 American Thyroid Association Management Guidelines for Adult Patients with Thyroid Nodules and Differentiated Thyroid Cancer: The American Thyroid Association Guidelines Task Force on Thyroid Nodules and Differentiated Thyroid Cancer. Thyroid 2016;26:1-133.

40. Sancho JJ, Lennard TW, Paunovic I, et al. Prophylactic central neck disection in papillary thyroid cancer: a consensus report of the European Society of Endocrine Surgeons (ESES). Langenbecks Arch Surg 2014;399:155-63.

41. Iacobone M, Jansson S, Barczynski M, et al. Multifocal papillary thyroid carcinoma--a consensus report of the European Society of Endocrine Surgeons (ESES). Langenbecks Arch Surg 2014;399:141-54.

42. Udelsman R, Westra WH, Donovan PI, et al. Randomized prospective evaluation of frozen-section analysis for follicular neoplasms of the thyroid. Ann Surg 2001;233:716-22.

43. Liang J, Li Z, Fang F, et al. Is prophylactic central neck dissection necessary for $\mathrm{cN} 0$ differentiated thyroid cancer patients at initial treatment? A meta-analysis of the literature. Acta Otorhinolaryngol Ital 2017;37:1-8.

44. Zhao W, You L, Hou X, et al. The Effect of Prophylactic Central Neck Dissection on Locoregional Recurrence in 
Papillary Thyroid Cancer After Total Thyroidectomy: A Systematic Review and Meta-Analysis: pCND for the Locoregional Recurrence of Papillary Thyroid Cancer. Ann Surg Oncol 2017;24:2189-98.

45. Lang BH, $\mathrm{Ng} \mathrm{SH}$, Lau LL, et al. A systematic review and meta-analysis of prophylactic central neck dissection on short-term locoregional recurrence in papillary thyroid carcinoma after total thyroidectomy. Thyroid 2013;23:1087-98.

46. Scerrino G, Attard A, Melfa GI, et al. Role of prophylactic central neck dissection in cN0-papillary thyroid carcinoma: results from a high-prevalence area. Minerva Chir 2016;71:159-67.

47. Hall CM, Snyder SK, Maldonado YM, et al. Routine central lymph node dissection with total thyroidectomy for papillary thyroid cancer potentially minimizes level VI recurrence. Surgery 2016;160:1049-58.

48. Adam MA, Pura J, Goffredo P, et al. Presence and Number of Lymph Node Metastases Are Associated With Compromised Survival for Patients Younger Than Age 45 Years With Papillary Thyroid Cancer. J Clin Oncol 2015;33:2370-5.

49. Nixon IJ, Wang LY, Palmer FL, et al. The impact of nodal status on outcome in older patients with papillary thyroid cancer. Surgery 2014;156:137-46.

50. Schneider DF, Chen H, Sippel RS. Impact of lymph node ratio on survival in papillary thyroid cancer. Ann Surg Oncol 2013;20:1906-11.

51. Zaydfudim V, Feurer ID, Griffin MR, et al. The impact of lymph node involvement on survival in patients with papillary and follicular thyroid carcinoma. Surgery 2008;144:1070-7; discussion 1077-8.

52. Podnos YD, Smith D, Wagman LD, et al. The implication of lymph node metastasis on survival in patients with welldifferentiated thyroid cancer. Am Surg 2005;71:731-4.

Cite this article as: Hargitai L, Strobl S, Koperek O, Urach S, Raber W, Staudenherz A, Scheuba C, Riss P. Positive central lymph-nodes are underdiagnosed in patients with Bethesda $\mathrm{V}$ cytology in an endemic goiter region. Gland Surg 2020;9(2):252260. doi: 10.21037 /gs.2020.02.07
53. Tran Cao HS, Johnston LE, Chang DC, et al. A critical analysis of the American Joint Committee on Cancer (AJCC) staging system for differentiated thyroid carcinoma in young patients on the basis of the Surveillance, Epidemiology, and End Results (SEER) registry. Surgery 2012;152:145-51.

54. Perrier ND, Brierley JD, Tuttle RM. Differentiated and anaplastic thyroid carcinoma: Major changes in the American Joint Committee on Cancer eighth edition cancer staging manual. CA Cancer J Clin 2018;68:55-63.

55. Kim M, Jeon MJ, Oh HS, et al. Prognostic Implication of N1b Classification in the Eighth Edition of the TumorNode-Metastasis Staging System of Differentiated Thyroid Cancer. Thyroid 2018;28:496-503.

56. Maksimovic S, Jakovljevic B, Gojkovic Z. Lymph Node Metastases Papillary Thyroid Carcinoma and their Importance in Recurrence of Disease. Med Arch 2018;72:108-11.

57. Nikiforov YE, Yip L, Nikiforova MN. New strategies in diagnosing cancer in thyroid nodules: impact of molecular markers. Clin Cancer Res 2013;19:2283-8.

58. Ozbas S, Kocak S, Aydintug S, et al. Comparison of the complications of subtotal, near total and total thyroidectomy in the surgical management of multinodular goitre. Endocr J 2005;52:199-205.

59. Zambudio AR, Rodriguez J, Riquelme J, et al. Prospective study of postoperative complications after total thyroidectomy for multinodular goiters by surgeons with experience in endocrine surgery. Ann Surg 2004;240:18-25.

60. Calo PG, Pisano G, Medas F, et al. Total thyroidectomy without prophylactic central neck dissection in clinically node-negative papillary thyroid cancer: is it an adequate treatment? World J Surg Oncol 2014;12:152. 